\title{
The Neural Cost of the Auditory Perception of Language Switches: An Event-Related Functional Magnetic Resonance Imaging Study in Bilinguals
}

\author{
Jubin Abutalebi, ${ }^{1}$ Simona M. Brambati, ${ }^{2}$ Jean-Marie Annoni, ${ }^{3}$ Andrea Moro, ${ }^{1}$ Stefano F. Cappa, ${ }^{1}$ and Daniela Perani ${ }^{1}$ \\ ${ }^{1}$ Centre for Cognitive Neuroscience, Vita-Salute San Raffaele University and San Raffaele Scientific Institute, 20132 Milan, Italy, ${ }^{2}$ Department of Neurology, \\ University of California, San Francisco, California 94143-1207, and ${ }^{3}$ Neuropsychology Unit, Department of Neurology, Geneva University Hospitals, \\ CH-1211 Geneva, Switzerland
}

\begin{abstract}
One of the most remarkable abilities of bilinguals is to produce and/or to perceive a switch from one language to the other without any apparent difficulty. However, several psycholinguistic studies indicate that producing, recognizing, and integrating a linguistic code different from the one in current use may entail a processing cost for the speaker/listener. Up to now, the underlying neural substrates of perceiving language switches are unknown. In the present study, we investigated the neural mechanisms of language switching during auditory perception in bilinguals. Event-related functional magnetic resonance imaging was performed in 12 early, highly proficient Italian/French bilinguals, who were more exposed to their second language. Subjects had to listen to narratives containing "switched passages" that could either respect (i.e., regular switches) or violate (i.e., irregular switches) the constituents of sentence structure. The results indicate that switching engages an extensive neural network, including bilateral prefrontal and temporal associative regions. Moreover, a clear dissociation is observed for the types of switches. Regular switches entail a pattern of brain activity closely related to lexical processing, whereas irregular switches engage brain structures involved in syntactic and phonological aspects of language processing. Noteworthy, when switching into the less-exposed language, we observed the selective engagement of subcortical structures and of the anterior cingulate cortex, putatively involved in cognitive and executive control. This suggests that switching into a less-exposed language requires controlled processing resources. This pattern of brain activity may constitute an important neural signature of language dominance in bilinguals.
\end{abstract}

Key words: bilinguals; language switching; event-related fMRI; language comprehension; auditory perception; cognitive control

\section{Introduction}

Bilingual subjects continuously face the challenge of controlling their two languages during communication to avoid interference from the nontarget language (Hernandez et al. 2005). There is an ongoing debate on how bilinguals correctly select the target language and on what neurocognitive mechanisms they rely. Most of the behavioral evidence about the nature of language selection comes from switching paradigms during language production (Amrhein, 1999; Hernandez and Kohnert, 1999; Meuter and Allport, 1999; Costa and Santesteban, 2004). In these tasks, participants are asked to name pictures alternating between their two languages. The difference in naming latencies between switch and nonswitch trials is referred to as the "language-switching cost."

In general, bilinguals have faster picture-naming latencies for their first language (L1) compared with their second language

Received April 16, 2007; accepted Aug. 23, 2007.

This work was supported by Schweizerische Nationalfonds/FNS Grant 3151A0-102271/1 (J.A., J.-M.A.) and a Programmi di Ricerca di Interesse Nazionale grant (S.F.C.). We are grateful to Marco Tettamanti and Paola Scifo for their technical assistance and to Judith F. Kroll, David W. Green, and Michel Paradis for useful suggestions.

Correspondence should be addressed to Dr. Jubin Abutalebi, Facoltà di Psicologia, Università Vita-Salute San Raffaele, Via Olgettina 58, 20132 Milan, Italy. E-mail: abutalebi.jubin@hsr.it.

DOI:10.1523/JNEUROSCI.3294-07.2007

Copyright $\odot 2007$ Society for Neuroscience $\quad 0270-6474 / 07 / 2713762-08 \$ 15.00 / 0$
(L2) (Christoffels et al., 2006). However, under languageswitching conditions, the difference in naming latencies between L1 and L2 may reverse, with shorter latencies for L2 (Meuter and Allport, 1999; Kroll et al., 2006). One explanation is that switching back into L1 is more difficult, because its lexical representations have been strongly inhibited to allow the selection of L2 items. Thus, part of the switching cost is a result of overcoming this inhibition. Switching into L2 is relatively easier because, when naming in L1, its corresponding lexical representation would be less inhibited and therefore more available (Green, 1998). However, the notion of inhibition during language selection is not universally accepted (Costa and Caramazza, 1999).

Neuroimaging may deepen our understanding of language selection. During a mixed naming condition, compared with monolingual naming, Hernandez et al. $(2000,2001)$ showed a selective engagement of the dorsolateral prefrontal cortex (see also Chee et al., 2003; Wang et al., 2007). Price et al. (1999) reported anterior cingulate cortex (ACC) and basal ganglia activity during word translation, and the supramarginal gyrus during switching. Because this network (prefrontal cortex, ACC, supramarginal gyrus, and basal ganglia) is related to cognitive control (Miller and Cohen, 2001), it was postulated that language selection involves cognitive control based on inhibitory mechanisms 
Table 1. Examples of the types of switches that occurred during the experiment: regular switches (left column) and irregular switches (right column)

\begin{tabular}{ll}
\hline Regular switches & Irregular switches \\
\hline IL PICCOLO PRINCIPE_qui m'a posé beaucoup de questions & mais le_PERICOLO DEI BAOBAB \\
(THE LITTLE PRINCE_who has asked me a lot of questions) & (but the_DANGER OF THE BAOBAB) \\
"Pourquoi vends tu ça,"_DISSE IL PICCOLO PRINCIPE & J'ai_RISPOSTO \\
("why do you sell this"_SAID THE LITTLE PRINCE) & (I have_ANSWERED) \\
"AH," DISSE IL PICCOLO PRINCIPE,_"ills sont bien jolis tes souvenirs" & CHE AVEVA_travaillé avec \\
("OH," SAID THE LITTLE PRINCE,_"your souvenirs are quite beautiful") & (WHO HAS_worked with) \\
IL PICCOLO PRINICPE INCONTRO'IL CONTROLLORE._"Buonjour," dit le & IL PICCOLO_prince était \\
petit prince & \\
(THE LITTLE PRINCE MET THE CONTROLLER._"Good-morning," said the & (THE LITTLE_prince was) \\
littlle prince) & \\
E MI DICEVO:_"Ce que je vois là" & mais s'était_INTERROTTO \\
(AND I WAS TELLING TO MYSELF:_"that what I see there") & (but it was_INTERRUPTED)
\end{tabular}

As may be seen in the examples, regular switches respected the constituents of sentence structure whereas irregular switches violated the constituents of the sentence structure. The Italian part is written in all capital letters whereas the French part is written in capital and lowercase letters. The underscore highlights the location where the switch took place.

(Abutalebi and Green, 2007). However, none of these studies addressed the neural substrates of language switching in comprehension. Only a few event-related potential (ERP) studies have investigated language switching in sentence comprehension (Moreno et al., 2002; Alvarez et al., 2003; Proverbio et al., 2004; Jackson et al., 2004), showing that switching, compared with nonswitching trials, elicited an increased N400 component over left frontocentral sites.

In the present study, we address the neural correlates of language switching during comprehension. Highly-proficient bilinguals differentially exposed to their languages, underwent eventrelated functional magnetic resonance imaging (er-fMRI) while listening to narratives containing unpredictable switches from L1 to L2 and vice versa. To assess the impact of sentence wellformedness on the switching mechanism, half of these switches respected, whereas the other half violated, the constituent structure of sentences.

Our main hypothesis is that regular switches are processed through neural pathways related to lexical-semantic processing, whereas irregular switches may rely more on phonological and morphosyntactic processes. Finally, we predict that switching into a less-exposed language may engage structures related to cognitive control.

\section{Materials and Methods \\ Subjects}

A group of 12 Italian/French bilinguals (six males; six females; mean age, 30.2; age range, 21-44) took part in the present study. All subjects came from Italian families living in Switzerland; thus, their mother language (L1) is Italian and their second language (L2) French. All subjects acquired their L2 before the age of three and may hence be considered early bilinguals. These subjects live in the Italian community of Geneva in Switzerland, where the predominant language is French.

All participants were right-handed, as assessed by the Edinburgh Inventory Scale (Oldfield, 1971), and had no history of neurological or psychiatric disorders. They were aware of the aims of the research and signed an informed consent. The experimental protocol followed the guidelines for human research developed by the ethical committees of the participating institutions and was approved by the local ethical committee.

\section{Behavioral study}

Subjects underwent a behavioral assessment aimed at investigating the respective level of language proficiency for L1 and L2 and the level of exposure to L1 and L2.
Semantic and grammatical judgment tests. The stimulus material consisted of 120 short sentences (60 French and 60 Italian sentences). One-half of the French and Italian sentences were grammatically and semantically correct. In both languages, the remaining half contained either grammatical or semantic violations. Thus, there were four conditions: French and Italian grammatical judgment and French and Italian semantic judgment. For the grammatical condition, the sentences were meaningful, but included different types of grammatical violations, either disagreement of number or gender [e.g., "I gatti [plural] ama [singular] cacciare i topi" (the cats [plural] likes [singular] hunting the mice)]. For the semantic condition, the sentences were grammatically correct, but contained semantic violations (e.g., "La pannocchia mangia il maiale" (the corncob eats the swine)]. All sentences were orthographically correct and matched for length and word frequency. The sentences were adapted from the corpus of sentences by Hahne and Friederici (2002). Three native speakers of French and Italian judged whether or not the sentences made sense or were violated, respectively. Only those sentences for which there was a $100 \%$ consensus were selected.

The sentences were presented for $1500 \mathrm{~ms}$ with an interstimulus interval of $4000 \mathrm{~ms}$ in four independent sessions, respectively, for grammatical judgment in French and Italian and for semantic judgment in French and Italian. Subjects were asked to press the "enter" button on the keyboard every time they detected sentences containing semantic or grammatical anomalies. Participants were asked to be as fast and accurate as possible. The stimuli were delivered and the reaction times were recorded by means of the software Presentation 0.81 (Neurobehavioral Systems, Davis, CA).

Word translation task. Subjects were invited to translate three lists of single words in each language (i.e., from French to Italian and vice versa). The lists included each an equal number $(n=30)$ of low-, medium-, and high-frequency words. Words belonging to the lists were matched for word length. Hence, 90 words were translated from L1 to L2 and vice versa.

Written comprehension. Participants were asked to read a short story in French and in Italian and to answer some questions concerning the content of each story. The stories were taken from the written parts of the "high-level diploma" certifications for both languages (Diplome Approfondi de Langue Française; Diploma Avanzato di Lingua Italiana).

Subjects also underwent an assessment of their level of exposure to L1 and L2. All subjects were asked to fill out a detailed questionnaire that investigated the subjects' present use of each language. The participants were asked to estimate how many hours per day they were exposed to each language. The questionnaire covered the following areas: media (television and radio), family (with each member), university (classmates and teaching), friends (not classmates), reading (newspapers and books), and other activities (hobbies, sports, music, etc.) (for details, see Wartenburger et al., 2003).

\section{Functional imaging study}

Experimental paradigm. An er-fMRI design was applied to an auditory language task. Subjects were invited to passively listen to four narratives containing sudden and unpredictable changes of language (i.e., switches), from Italian to French and vice versa. These switches were the main events to be investigated by means of er-fMRI. The "switched passages" were obtained by cutting and pasting fragments from monolingual recordings selected from the story The Little Prince (Le Petit Prince; Il Piccolo Principe) (De Saint-Exupery, 1949a,b). A balanced bilingual professional reader recorded both the Italian and French version of the passages. To assure that the bilingual reader was free of any specific language-related accent, five monolingual subjects for each language in the study evaluated whether the speaker had an accent or not. 
Each of the four stories included a total of 60 language switches (30 $\mathrm{L} 1 \rightarrow \mathrm{L} 2$ and $30 \mathrm{~L} 2 \rightarrow \mathrm{L} 1$ ), making a total of 240 switches, 120 of them being L1 $\rightarrow$ L2 switches and $120 \mathrm{~L} 2 \rightarrow \mathrm{L} 1$ switches. The sentence duration (intervals between language switches) was variable, from a minimum of 3 to a maximum of $19 \mathrm{~s}$, not allowing the listener to form expectations of the language switches. We further checked that switches never occurred in the proximity of homophones and pseudohomophones. Likewise, switches between French and Italian, and vice versa, never occurred on cognate words.

Two of the stories contained only switches that respected the constituents of sentence structures (henceforth referred to as "regular switches"); in other words, in the sentence containing the switch "Il piccolo principe_est allé" ("the little prince_was going"; language switch marked with the underscore) the noun-verb constituents are respected. The remaining two stories contained only switches that did not respect the constituents of sentence structure (henceforth called "irregular switches"). In the sentence "J'ai_risposto" ("I have_answered"), the switch is between the Italian verb and the French auxiliary and, hence, not respecting the constituent structure (for examples of switches, see Table 1). Thus, in the two stories with irregular switches, the language switch was placed inside the constituents and, in particular, inside the noun phrase and the verb phrase. Within the noun phrase, switches were located between the determiner and the noun, between the adjective phrase and the noun, between the determiner and the adjective, or inside the adjective phrase. Within the verb phrase, switches were located between the auxiliary verb and the participle of the lexical verb, and between the clitic (that can replace, for example, the noun phrase or prepositional phrase) and the verb.

Of the total amount of 120 irregular switches, 68 switches were located inside the verb phrase ( 39 between the clitic and the verb, and 29 between the auxiliary verb and the lexical verb), whereas 52 switches were located inside the noun phrase.

To summarize, from the grand total of 240 switches, 60 switches were regular switches from L1 to L2, 60 switches were regular switches from L2 to L1, 60 switches were irregular switches from L1 to L2, and 60 switches were regular switches from L2 to L1. The subjects were not informed that switches could be regular or irregular.

The order of presentation of the four stories was randomized among subjects. Moreover, to keep high the level of attention during fMRI scanning, subjects were told that at the end of the experiment they would be asked to fill out a questionnaire with 10 questions regarding the content of the stories.

Scanning procedures. MRI scans were performed on a $1.5 \mathrm{~T}$ General Electric (Milwaukee, WI) Signal Horizon system with a standard head coil. Spin echo sagittal scans were acquired to localize the anterior and posterior commissures on the midline sagittal section. Twenty transverse T1-weighted spin echo images were acquired along the bicommissural plane [echo time (TE), $14 \mathrm{~ms}$; repetition time (TR), $350 \mathrm{~ms}$ ]. Field homogeneity was adjusted by means of "global shimming" for each subject. Thereafter, 290 echo planar volumes for each session were acquired using an echo planar imaging (EPI) gradient echo sequence (TR, $2500 \mathrm{~ms}$; TE, $60 \mathrm{~ms}$; field of view, $256 \times 256$; matrix, $64 \times 64$; number of slices, 20 ; thickness, $5 \mathrm{~mm}$ ).

Image processing. All preprocessing steps and statistical analysis were performed with SPM2 (http://www.fil.ion.ucl.ac.uk/spm; Wellcome Department of Cognitive Neurology, London, UK), running on Matlab 6.5 (Math Works, Natick, MA). The first 10 volumes of each section were discarded from the analysis to include only the EPI images with an optimized signal.

Slice-timing procedures were applied to all EPI images to correct for differences in acquisition time between slices. For each subject, all the acquired data were realigned to the first image of the first session to neutralize effects of intrasession and intersession movements. The anatomical volume was realigned to the first EPI volume. The realigned images were "normalized" into Montreal Neurological Institute (MNI) stereotactic space. The normalization parameters were estimated by matching the realigned anatomical volume with a standard $\mathrm{T} 1$ template. The parameters were then applied to the realigned functional and anatomical volumes, obtaining normalized volumes with a voxel size of $2 \times$
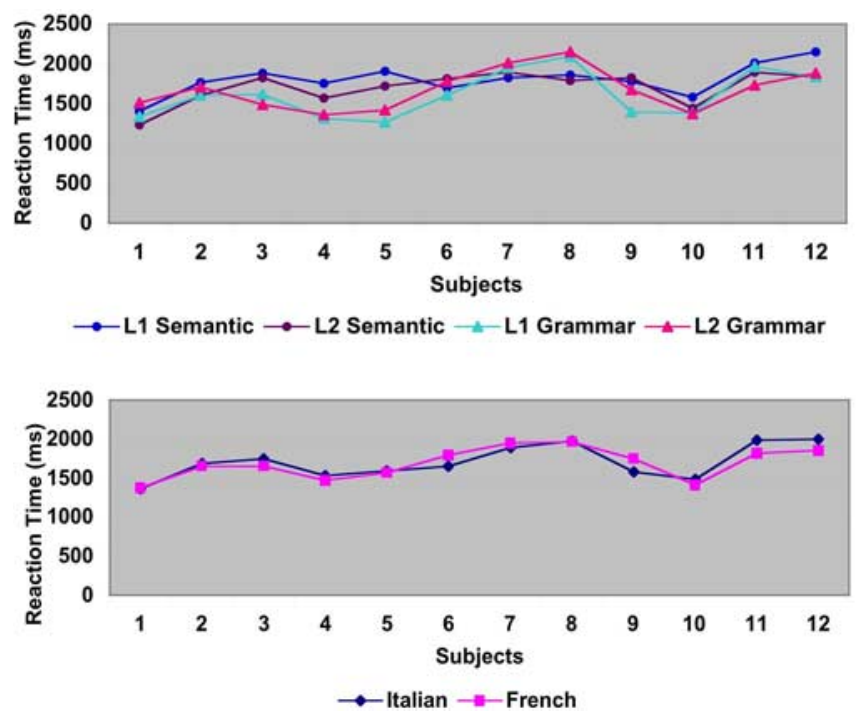

Figure 1. The figure illustrates the psycholinguistic background of the early bilinguals in the present study. Reaction times for the semantic and grammatical judgment tasks are reported on top whereas the combined results related to $\mathrm{L} 1$ and $\mathrm{L} 2$ are reported on the bottom (for details, see Results).

$2 \times 5 \mathrm{~mm}$. All of the images were then smoothed with a Gaussian kernel of $8 \times 8 \times 8 \mathrm{~mm}$ to increase the signal-to-noise ratio.

Statistical analysis. Image preprocessing and statistical analysis were performed using SPM2 implemented in Matlab 6.5. The effects of the experimental design were assessed on a voxel-by-voxel basis using the general linear model. Statistical maps were generated using a randomeffect model (Friston et al., 1999), implemented in a two-level procedure. At the first level, single-subject fMRI responses were modeled by a design matrix comprising the onset of the language switches. Regressors modeling events were convolved with a canonical hemodynamic response function (HRF), along with its temporal and dispersion derivatives, and parameter estimates for all regressors were obtained by maximumlikelihood (ML) estimation.

At the second level, random-effects group analyses across the 12 subjects were computed. Statistical parametric maps for the simple main effects were generated by an ANOVA incorporating the HRF and its derivatives for each condition (corrected for nonsphericity using a restricted ML procedure (Friston et al., 2002). Four simple main effects were then analyzed: (1) regular switches into L1 (L2 $\rightarrow \mathrm{L} 1),(2)$ regular switches into L2 (L1 $\rightarrow$ L2), (3) irregular switches into L1 $(\mathrm{L} 2 \rightarrow \mathrm{L} 1)$, and (4) irregular switches into L2 $(\mathrm{L} 1 \rightarrow \mathrm{L} 2)$.

The resulting statistical maps were then used to perform a conjunction analysis, which tests for regions activated by all of the switching tasks.

Direct comparisons between tasks were performed using paired $t$ tests on images of the contrasts of HRF parameter estimates: (1) regular switches into L1 (L2 $\rightarrow$ L1 switches) versus regular switches into L2 (L1 $\rightarrow$ L2 switches), (2) regular switches into L2 ( $1 \rightarrow$ L2 switches) versus regular switches into L1 (L2 $\rightarrow$ L1 switches), (3) irregular switches into L1 (L2 $\rightarrow$ L1 switches) versus irregular switches into L2 (L1 $\rightarrow$ L2 switches), and (4) irregular switches into L2 (L1 $\rightarrow$ L2 switches) versus irregular switches into L1 (L2 $\rightarrow$ L1 switches).

All of the statistical maps were thresholded at $p<0.005$ (not corrected). An extent threshold of 20 contiguous voxels was applied to all contrasts. All of the coordinates derived from the statistical analysis were converted from MNI to Talairach and Tournoux stereotaxic space (Talairach and Tournoux, 1988). Stereotactical coordinates belonging to activation foci found in the frontal lobes were further controlled and adjusted by means of probabilistic cytoarchitectonic maps (Eickhoff et al., 2005). 
Table 2. Stereotactic coordinates of the simple main effects of the four types of switches

\begin{tabular}{|c|c|c|c|c|}
\hline Anatomical location & $x$ & $y$ & $Z$ & Z-value \\
\hline \multicolumn{5}{|l|}{ Regular switches into L1 } \\
\hline L middle frontal gyrus (Ba 45) & -40 & 16 & 32 & 3.62 \\
\hline L superior frontal gyrus (Ba 9) & -6 & 48 & 38 & 4.26 \\
\hline \multirow[t]{2}{*}{ L anterior cingulate cortex ( $\mathrm{Ba} 32$ ) } & -4 & 40 & 18 & 3.99 \\
\hline & -16 & 44 & 16 & 3.30 \\
\hline Left angular gyrus (Ba 39) & -44 & -66 & 36 & 3.18 \\
\hline Left precuneus (Ba 7) & -12 & -50 & 34 & 3.51 \\
\hline L superior temporal gyrus ( $\mathrm{Ba} 22$ ) & -42 & -56 & 12 & 4.33 \\
\hline L superior temporal sulcus (Ba 22) & -62 & -48 & 8 & 4.65 \\
\hline L middle temporal gyrus ( $\mathrm{Ba} 21$ ) & -58 & -24 & -10 & 5.90 \\
\hline L inferior temporal gyrus (Ba 37) & -38 & -52 & -18 & 3.70 \\
\hline L thalamus & -22 & -26 & 4 & 3.35 \\
\hline L head of caudate & -2 & 10 & 14 & 2.93 \\
\hline L putamen & -28 & -12 & 10 & 3.01 \\
\hline \multirow[t]{2}{*}{ R inferior frontal gyrus (Ba 45) } & 56 & 22 & 6 & 4.23 \\
\hline & 52 & 30 & 2 & 3.94 \\
\hline R middle frontal gyrus ( $\mathrm{Ba} 45$ ) & 54 & 20 & 24 & 3.34 \\
\hline R anterior superior temporal gyrus ( $\mathrm{Ba} 22$ ) & 48 & -10 & 4 & 3.84 \\
\hline \multirow{3}{*}{ R temporal gyrus ( $\mathrm{Ba} 21$ ) } & 56 & -20 & -8 & 5.41 \\
\hline & 56 & -32 & -6 & 5.21 \\
\hline & 56 & -50 & 4 & 3.40 \\
\hline R globus pallidum & 14 & -6 & -2 & 3.34 \\
\hline R putamen & 28 & -6 & 8 & 3.09 \\
\hline \multicolumn{5}{|l|}{ Regular switches into L2 } \\
\hline L inferior frontal gyrus (Ba 45) & -40 & 12 & 30 & 3.59 \\
\hline L superior frontal gyrus (Ba 9) & -8 & 50 & 40 & 3.58 \\
\hline L superior temporal sulcus (Ba 22) & -60 & -40 & 6 & 4.55 \\
\hline \multirow[t]{2}{*}{ L middle temporal gyrus ( Вa 21) } & -52 & -18 & -8 & 6.59 \\
\hline & -58 & -24 & -10 & 6.54 \\
\hline L inferior temporal gyrus (Ba 37) & -42 & -60 & -12 & 3.26 \\
\hline \multirow[t]{2}{*}{ R inferior frontal gyrus ( $\mathrm{Ba} 45$ ) } & 56 & 22 & 6 & 4.11 \\
\hline & 56 & 22 & 16 & 3.52 \\
\hline \multirow[t]{2}{*}{ R temporal gyrus ( $\mathrm{Ba} 21)$} & 58 & -18 & -6 & 6.18 \\
\hline & 56 & -32 & -4 & 5.79 \\
\hline R temporal pole (Ba 38) & 50 & 8 & -16 & 5.64 \\
\hline \multicolumn{5}{|l|}{ Irregular switches into L1 } \\
\hline L inferior frontal gyrus (Ba 45) & -54 & 18 & 22 & 3.22 \\
\hline L inferior frontal gyrus (Ba 44, pars opercularis) & -48 & 16 & 6 & 3.26 \\
\hline \multirow[t]{2}{*}{ L LIPL (Ba 40) } & -44 & -50 & 44 & 3.53 \\
\hline & -50 & -44 & 38 & 3.49 \\
\hline \multirow[t]{2}{*}{ L middle temporal gyrus ( $\mathrm{Ba} 21$ ) } & -60 & -22 & -8 & 4.96 \\
\hline & -60 & -40 & -8 & 3.29 \\
\hline R inferior frontal gyrus (Ba 45) & 56 & 18 & 22 & 4.18 \\
\hline \multirow[t]{2}{*}{ R middle frontal gyrus ( $\mathrm{Ba} 6)$} & 44 & 4 & 50 & 3.68 \\
\hline & 54 & 10 & 40 & 3.13 \\
\hline R insula & 36 & 22 & -6 & 3.07 \\
\hline \multirow[t]{2}{*}{ R middle temporal gyrus ( $\mathrm{Ba} 21$ ) } & 68 & -46 & -2 & 4.16 \\
\hline & 56 & -32 & -6 & 3.31 \\
\hline R temporal pole (Ba 38) & 52 & 8 & -16 & 4.72 \\
\hline Irregular switches into L2 & & & & \\
\hline L middle frontal gyrus (Ba 45) & -50 & 22 & 24 & 3.90 \\
\hline L inferior frontal gyrus (Ba 44, pars opercularis) & -50 & 16 & 10 & 3.37 \\
\hline & -44 & 14 & 26 & 3.79 \\
\hline L superior frontal gyrus (Ba 6, pre-SMA) & -2 & 10 & 56 & 3.02 \\
\hline L LIPL (Ba 40) & -38 & -52 & 42 & 3.43 \\
\hline L middle temporal gyrus (Ba 21) & -58 & -24 & -10 & 4.42 \\
\hline & -64 & -34 & -4 & 3.83 \\
\hline R inferior frontal gyrus (Ba 45) & 56 & 22 & 6 & 3.93 \\
\hline & 52 & 36 & 8 & 3.81 \\
\hline R middle frontal gyrus ( $\mathrm{Ba} 45$ ) & 54 & 20 & 24 & 3.75 \\
\hline & 42 & 8 & 34 & 3.15 \\
\hline R middle frontal gyrus ( $\mathrm{Ba} 6$ ) & 52 & 10 & 42 & 3.28 \\
\hline R middle temporal gyrus ( $\mathrm{Ba} 21$ ) & 68 & -46 & -2 & 4.19 \\
\hline & 64 & -40 & -6 & 3.40 \\
\hline & 58 & -32 & -6 & 3.40 \\
\hline R temporal pole (Ba 38) & 52 & 8 & -16 & 3.90 \\
\hline
\end{tabular}

L, Left; R, right.

\section{Results}

Behavioral results

The results of the reaction-times study of the semantic and grammatical judgment tasks are depicted in Figure $1 A$. No significant difference was found between the two languages (Fig. 1). Moreover, a quite similar pattern of performance was observed in the word lists to be translated from L1 to L2 and vice versa. On average, in the case of high-frequency words, 29.83 out of 30 words and 29.66 of 30 words were correctly translated, respectively, from L2 to L1 and from L1 to L2. On the lists of medium-frequency words, 28.75 of 30 words and 27.58 of 30 words were correctly translated, respectively, from L2 to L1 and from L1 to L2. Finally, on the lists of low-frequency words, subjects correctly translated 16.88 of 30 words and 16.33 of 30 words, respectively, from $\mathrm{L} 2$ to $\mathrm{L} 1$ and from $\mathrm{L} 1$ to L2. As for the written comprehension tasks, the mean score for the L1 story was 7.78 of a maximum score of 8.0 whereas the mean score for L2 was 7.92 of a maximum of 8.0. The difference between L1 and L2 was not significant.

A significant difference was observed regarding the exposure to each language. Subjects' average exposure was $14.49 \%$ to their $\mathrm{L} 1$, and $85.51 \%$ to their $\mathrm{L} 2(t=5,264$; $p<0,0001)$. To summarize, the subjects were a group of early and highly proficient bilinguals significantly less exposed to their L1.

\section{Functional neuroimaging results}

The patterns of brain activity individually associated to each of the four types of switches calculated by means of the simple main effects are reported in Table 2 for region details and stereotactic coordinates, and illustrated in Figure 2. The simple main effect of regular switches into L1 (i.e., the less-exposed language) revealed an extensive pattern of activity in the left hemisphere, comprising the prefrontal [Brodmann's area (Ba) 45, Ba 9], parietal ( $\mathrm{Ba} 39, \mathrm{Ba} 7$ ), and temporal ( $\mathrm{Ba} 22$, Ba 21, Ba 37) cortex. The anterior cingulate cortex ( $\mathrm{Ba} 32)$, the basal ganglia (head of caudate and putamen), and the thalamus were also activated. In the right hemisphere, activity was found in the prefrontal ( $\mathrm{Ba} 45$ ) and temporal ( $\mathrm{Ba} 22, \mathrm{Ba} 21)$ cortex, and in the putamen. The simple main effect of regular switches into L2 revealed a pattern of brain activity similar, but less extended in terms of number of voxels (Table 2, Fig. 2, top right). The simple 
main effect of irregular switches into L1 (i.e., the less-exposed language) resulted in left hemispheric activation in the inferior frontal gyrus [ $\mathrm{Ba} 45$ and pars opercularis of Broca's area ( $\mathrm{Ba} 44)]$, the left inferior parietal lobule (LIPL; Ba 40), and the middle temporal gyrus ( $\mathrm{Ba} 21$ ). In the right hemisphere, the activation was located in the inferior ( $\mathrm{Ba} 44 / 45$ ) and middle frontal ( $\mathrm{Ba} 6)$ gyri, the insula, the middle temporal gyrus ( $\mathrm{Ba} 21$ ), and the temporal pole ( $\mathrm{Ba} 38$ ). The simple main effect of irregular switches into L2 was associated with activation in comparable regions as for irregular switches into L1, namely Ba 45 and the pars opercularis of Broca's area ( $\mathrm{Ba} 44$ ), the LIPL ( $\mathrm{Ba} 40$ ), and the left middle temporal gyrus ( $\mathrm{Ba} 21$ ). Similar activations were observed in the right hemisphere.

The conjunction analysis on all four types of switches (i.e., regular switches into L1, regular switches into L2, irregular switches into L1, and irregular switches into L2) showed a pattern of brain activity comprising the left inferior frontal gyrus

(Ba 45, $x=-48, y=20, z=22$ ) the left anterior middle temporal gyrus ( $\mathrm{Ba} 21, x=-58, y=-24, z=-10$ ), and the left posterior middle temporal gyrus ( $\mathrm{Ba} 21 / 37, x=-60, y=-44, z=-12$ ). In the right hemisphere, the activation involved the homolog temporal areas ( $\mathrm{Ba} 21, x=56, y=-22, z=-10$; Ba 21/37, $x=66, y=-46, z=-2)$, the right inferior frontal gyrus ( $\mathrm{Ba}$ $45, x=56, y=20, z=12$ ), and the middle frontal gyrus ( $\mathrm{Ba}$ 45/46, $x=54, y=32, z=20$ ) (Fig. 3).

The direct comparisons, performed to detect differences between languages revealed the following patterns of activity (Fig. 4). Regular switches into L1 compared with those into L2 activated the left caudate nucleus $(x=-8, y=6, z=8)$, and bilaterally, the anterior cingulate ( $\mathrm{Ba} 32, x=-6, y=24, z=$ 20; $\mathrm{Ba} 24, x=12, y=40, z=18)$ and posterior cingulate cortex ( $\mathrm{Ba} 23, x=-8, y=-56, z=18$, and $x=18, y=-52$, $z=16$ ) and the right supramarginal gyrus ( $\mathrm{Ba} 39, x=48, y=$ $-58, z=36$ ). The reverse comparison (i.e., regular switches into L2 compared with those into L1) revealed a different pattern of activity involving the left superior parietal lobule (Ba 7, $x=-26, y=-64, z=54$ ), the left anterior superior temporal gyrus (temporal pole; $\mathrm{Ba} 22, x=-52, y=-14, z=$ $6)$, and the right temporal pole ( $\mathrm{Ba} 38, x=50, y=4, z=-10)$. When comparing the irregular switches into the less-exposed language (L1) to those into L2 we found again the engagement of the head of the left caudate $(x=-20, y=16, z=0)$, and bilaterally of the anterior cingulate cortex $(x=-6, y=20, z=$ 32 ; and $x=8, y=30, z=14$ ). Additional foci of activity were found in the left insula ( $\mathrm{Ba} 44, x=-46, y=0, z=2$ ), the left superior temporal gyrus ( $\mathrm{Ba} 22, x=-56, y=-32, z=6$ ), and the right middle temporal gyrus ( $\mathrm{Ba} 21, x=36, y=-68, z=$ $2)$. The irregular switches into L2 compared with those into L1 entailed brain activation in the left superior frontal gyrus ( $\mathrm{Ba}$ $10, x=-22, y=62, z=10)$, the LIPL (Ba 40, $x=-40, y=$ $-32, z=48$ ), the left precuneus ( $\mathrm{Ba} 7, x=-4, y=-54$, $z=36$ ), and the right precentral gyrus ( $\mathrm{Ba} 6, x=58, y=-16$, $z=36$ ).

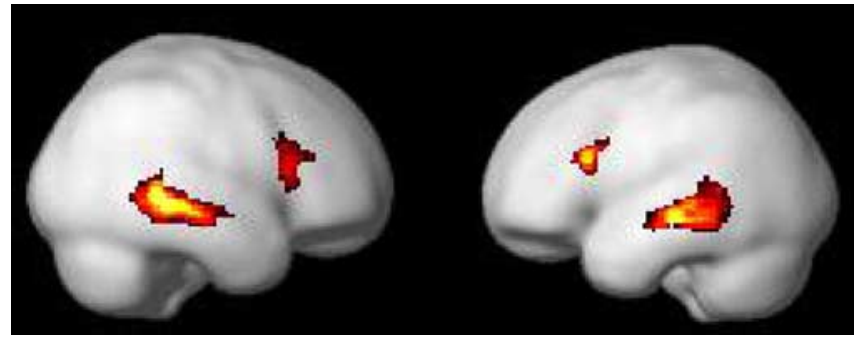

Figure 3. Pattern of brain activity revealed by the conjunction analysis between all four types of switches.

\section{Discussion}

The auditory perception of language switches

Both regular and irregular switches, as shown by the conjunction analysis, activated bilaterally the inferior prefrontal and superior temporal cortex. The event-related paradigm of the present study allows precise detection of the switches (events of interest), leaving out the comprehension processes of the narratives serving as a baseline. The brain correlates of passively listening to narratives, however, have been extensively studied in monolinguals (Scott et al., 2000; Crinion et al., 2003; Scott, 2005; Spitsyna et al., 2006) and in bilinguals (Perani et al., 1996, 1998). A common finding of these studies is the extensive engagement of the temporal lobes from Wernicke's area along the superior and middle temporal gyri to the temporal poles. This latter region is specifically engaged for linguistic integration at the discourse level (Scott et al., 2000; Humphries et al., 2001) and was also found for L2 in highly proficient bilinguals, but not in low-proficient bilinguals (Perani et al., 1998). The absence of these areas in the present study might not only be because of the experimental paradigm, but may also be a consequence of susceptibility artifacts of $\mathrm{fMRI}$ in these anterior temporal regions (Devlin et al.,2000),

The engagement of the inferior prefrontal cortex seems to be specific for the switching conditions. Indeed, passive listening to 


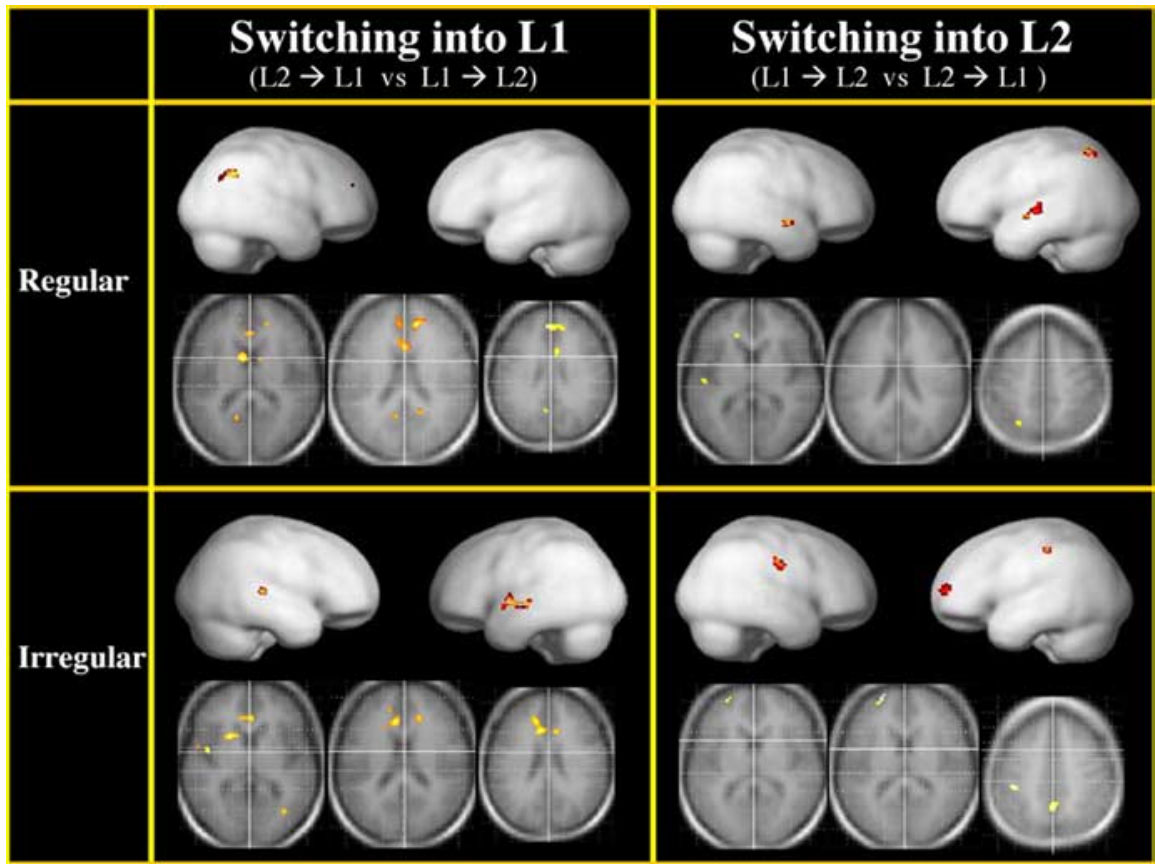

Figure 4. Direct comparisons between languages ( $\mathrm{L} 1$ and $\mathrm{L} 2$ ) and types of switches (regular and irregular). Regular switches into the less-exposed language (L1) compared with those into L2 (top, left) activated a network of brain areas associated with cognitive control (for details, see text). This pattern was found also for irregular switches into the less-exposed language (L1) compared with those into L2 (bottom, left). The reverse comparisons, i.e., regular switches into L2 compared with those into L1 (top, right) and irregular switches into L2 compared with those into L1 (bottom, right), did not engage this network of brain areas. grammatical violations (for example, to check the number/gender congruency between the L1 auxiliary and the L2 verb), and finally in a check of whether the sentence makes sense. This hypothesis may explain the engagement of the pars opercularis of Broca's area and the LIPL, the neural counterpart of the phonological loop (Paulesu et al., 1993; Smith and Jonides, 1999), and of syntactical analysis (Friederici et al., 2003).

\section{Language control in bilinguals}

We suggest that the activity found in the caudate nucleus and the ACC when switching into the weaker (i.e., lessexposed) language is related to cognitive control mechanisms and may reflect, at the neural level, the switching cost. However, our study could not confirm the psycholinguistic evidence that the switch cost arises when switching in the weak to dominant language direction (Meuter and Allport, 1999). Several ERPs studies found, as in the present study, an opposite asymmetric pattern of switching costs: increased N400 amplitude in the dominant to weak but not in the weak to dominant language direction (Alvarez et al., 2003; Proverbio et al., 2004). One explanation is that, whereas most of psycholinguistic narratives does not engage the inferior prefrontal cortex. Only when incorporating explicit metalinguistic tasks into experimental designs (such as decision tasks) is prefrontal activity reported (Crinion et al., 2003). Perceiving a language switch may be analogous to a metalinguistic task because, for the correct linguistic integration, subjects have to keep in mind the word on which the switch takes place. The activity within the prefrontal cortex may reflect executive control over access to short- or long-term memory representations (Thompson-Schill et al., 1997; Fletcher et al., 1998) such as semantic, phonological, or syntactic representations to assist comprehension (Dapretto and Bookheimer, 1999).

When considering individually regular and irregular switches, crucial differences emerged. The activation of regions related to lexical processing, such as the left Ba 37, was specific for regular switches, whereas irregular switches resulted in the activation of the opercular portion of Broca's area and the LIPL. The role of $\mathrm{Ba}$ 37 in lexical-semantic processing has been extensively demonstrated (Démonet et al., 2005) whereas the opercular portion of Broca's area and the LIPL have been linked to phonological processing (Paulesu et al., 1993) and to syntactic processing (Caplan et al., 2000; Friederici, 2002).

We hypothesize that regular switches may be treated as translation equivalents and, hence, as lexical alternatives (Green, 1998) immediately available to the bilingual listener. Conversely, irregular switches may not be immediately processed as lexical alternatives, but rather first as violations because of their occurring in unnatural and irregular positions. With the irregular switch "the dog is_abbaiando" (Italian for "is barking"), the bilingual speaker is faced with a harder problem: matching the English auxiliary to the Italian progressive form. Thus, violating the well-formedness of the sentence structure may result in a greater phonological workload and in the need to control for work on switching derives from production tasks, these ERPs investigations used a comprehension paradigm. We suggest that during comprehension in the weak language, the dominant language is not actively inhibited because comprehension is a more passive task and competition between languages may not be as prominent as in production. Hence, the switch cost would not arise to overcome the inhibition of the dominant language during comprehension in the weak language, but rather may be related to the necessity of strongly activating the weak language during the dominant to weak language switch. It should also be mentioned that ERPs studies focusing on production showed contrasting results to the behavioral literature. For instances, Jackson et al. (2001) found a significant frontal N2-effect only in the dominant to weak language direction, whereas Christoffels et al. (2007) revealed an equal cost for both directions. Interestingly, a previous fMRI study in language production reported that only switching into the weaker language is paralleled by ACC and prefrontal activity (Wang et al. 2007). Additional controlled investigations may shed light whether switching incurs a greater "neural cost" during the L1 to L2 switch or during the L2 to L1 switch.

As reported in neuroimaging studies during word production, the prefrontal cortex (Hernandez et al., 2000, 2001; RodriguezFornells et al., 2002, 2005; Chee et al., 2003), the caudate nuclei (Price et al., 1999; Crinion et al., 2006; Wang et al., 2007), and the ACC (Price et al., 1999; Wang et al., 2007) are engaged when bilinguals face potential language interference. It is remarkable that we found a similar cognitive control network using a passive auditory comprehension paradigm. This finding may lead to the conclusion that the bilingual brain is equipped with a dedicated control mechanism responsible for language selection. Moreover, by using a natural language paradigm, such as listening to 
narratives, we may exclude that our findings are purely related to the experimental task (Paradis, 2004). Noteworthy, the study of bilingual aphasia provides additional evidence that language control is a salient aspect of bilingual language processing. Focal lesions either to the left caudate or to the prefrontal cortex may lead to unintentional switches between languages and to nontarget language interference in naming tasks (Abutalebi et al., 2000; Mariën et al., 2005).

Language control is closely related to cognitive control and this complex function emerges from the interaction of separable systems such as the ACC, the caudate, and the left prefrontal cortex (Miller and Cohen, 2001). In particular, the ACC may act as a sensor of cognitive conflict (Botvinick et al., 1999, 2001) and modulates cognitive control (Bush et al., 2000). Conflict during language switching may arise when leaving a strong language system and entering a relatively weak language, such as the lessexposed L1 in the case of our study. As for the caudate nucleus, it has been shown previously that caudate activity increases proportionally to the degree to which a new salient sound interferes with the current cognitive focus (Zink et al., 2006). It may be hypothesized that the less-exposed language in our study was perceived as a more salient stimulus, requiring the reallocation of cognitive resources through more controlled processing.

On a first view, it may be surprising that in the present study L1 appears to require controlled processing. It is generally believed that language processing is mostly automatic in L1, whereas processing an L2 is more conscious and effortful (Segalowitz and Hulstijn, 2005). However, our subjects lived since their childhood in a predominantly L2 environment, a factor that had an important impact on their L1 exposure. Differential exposure may result in neural differences in the bilingual brain (Perani et al., 2003; Perani and Abutalebi, 2005) and exposure is assumed to be among the most relevant factors to determine which language recovers first in the case of bilingual aphasia (Paradis, 1998).

Similarly to proficiency, exposure may have strong influences on language interdependency in bilinguals. Kroll and Stewart (1994) proposed that there is an L1-dependency of L2, because an L2 is generally acquired with reference to existing L1 concepts (i.e., an L2 is mediated through L1 translation whereas L1 is concept mediated). Increasing L2 proficiency may result in less $\mathrm{L} 1$ dependency. It was shown that $\mathrm{L} 2$ can even replace L1 when bilinguals are no more exposed to L1 (Pallier et al., 2003). In our subjects, it is plausible that, despite an equal performance on proficiency testing, $\mathrm{L} 2$ replaced $\mathrm{L} 1$ as the dominant language because of the lack of a sufficient exposure to L1.

We may thus conclude that decreased exposure to a given language enhances controlled processing for that language. At the neural level, controlled processing may be indexed by activity in neural structures related to cognitive control, such as the left caudate and the ACC. In other words, the left caudate and ACC activity may constitute an important signature of language dominance in the bilingual brain. This index may be independent of language modality because it is not confined to language production, but is also involved in language comprehension.

\section{References}

Abutalebi J, Green D (2007) Bilingual language production: the neurocognition of language representation and control. J Neurolinguistics 20:242-275.

Abutalebi J, Miozzo A, Cappa SF (2000) Do subcortical structures control "language selection" in polyglots? Evidence from pathological language mixing. Neurocase 6:51-56.

Alvarez RP, Holcomb PJ, Grainger J (2003) Accessing word meaning in two languages: an event-related brain potential study of beginning bilinguals Brain Lang 87:290-304.

Amrhein PC (1999) On the functional equivalence of monolinguals and bilinguals in "monolingual mode": the bilingual anticipation effect in picture-word processing. Psychol Sci 10:230-236.

Botvinick M, Nystrom LE, Fissell K, Carter CS, Cohen JD (1999) Conflict monitoring versus selection-for-action in anterior cingulate cortex. Nature 402:179-181.

Botvinick MM, Braver TS, Barch DM, Carter CS, Cohen JD (2001) Conflict monitoring and cognitive control. Psychol Rev 108:624-652.

Bush G, Luu P, Posner MI (2000) Cognitive and emotional influences in anterior cingulate cortex. Trends Cogn Sci 4:215-222.

Caplan D, Alpert N, Waters G, Olivieri A (2000) Activation of Broca's area by syntactic processing under conditions of concurrent articulation. Hum Brain Mapp 9:65-71.

Chee MW, Soon CS, Ling Lee H (2003) Common and segregated neuronal networks for different languages revealed using functional magnetic resonance adaptation. J Cogn Neurosci 15:85-97.

Christoffels IK, De Groot AM, Kroll JF (2006) Memory and language skills in simultaneous interpreters: the role of expertise and language proficiency. J Mem Lang 54:324-345.

Christoffels IK, Firk C, Schiller NO (2007) Bilingual language control: an event-related brain potential study. Brain Res 1147:192-208.

Costa A, Caramazza A (1999) Is lexical selection in bilinguals languagespecific? Further evidence from Spanish-English bilinguals and EnglishSpanish bilinguals. Bilingualism Lang Cogn 2:231-244.

Costa A, Santesteban M (2004) Lexical access in bilingual speech production: evidence from language switching in highly proficient bilinguals and L2 learners. J Mem Lang 50:491-511.

Crinion J, Turner R, Grogan A, Hanakawa T, Noppeney U, Devlin JT, Aso T, Urayama S, Fukuyama H, Stockton K, Usui K, Green DW, Price CJ (2006) Language control in the bilingual brain. Science 312:1537-1540.

Crinion JT, Lambon-Ralph MA, Warburton EA, Howard D, Wise RJ (2003) Temporal lobe regions engaged during normal speech comprehension. Brain 126:1193-1201.

Dapretto M, Bookheimer SY (1999) Form and content: dissociating syntax and semantics in sentence comprehension. Neuron 24:427-432.

Démonet JF, Thierry G, Cardebat D (2005) Renewal of the neurophysiology of language: functional neuroimaging. Physiol Rev 85:49-95.

De Saint-Exupery A (1949a) Il Piccolo Principe. Milan: Tascabili Bompiani. De Saint-Exupery A (1949b) Le Petit Prince. Paris: Gallimard.

Devlin JT, Russell RP, Davis MH, Price CJ, Wilson J, Moss HE, Matthews PM, Tyler LK (2000) Susceptibility-induced loss of signal: Comparing PET and fMRI on a semantic task. NeuroImage 11:589-600.

Eickhoff SB, Stephan KE, Mohlberg H, Grefkes C, Fink GR, Amunts K, Zilles K (2005) A new SPM toolbox for combining probabilistic cytoarchitectonic maps and functional imaging data. NeuroImage 25:1325-1335.

Fletcher PC, Shallice T, Dolan RJ (1998) The functional roles of prefrontal cortex in episodic memory: I. Encoding. Brain 121:1239-1248.

Friederici AD (2002) Towards a neural basis of auditory sentence processing. Trends Cogn Sci 6:78-84.

Friederici AD, Ruschemeyer SA, Hahne A, Fiebach CJ (2003) The role of left inferior frontal and superior temporal cortex in sentence comprehension: localizing syntactic and semantic processes. Cereb Cortex 13:170-177.

Friston KJ, Holmes AP, Price CJ, Buchel C, Worsley KJ (1999) Multisubject FMRI studies and conjunction analyses. NeuroImage 10:385-396.

Friston KJ, Glaser DE, Henson RN, Kiebel S, Phillips C, Ashburner J (2002) Classical and Bayesian inference in neuroimaging: applications. NeuroImage 16:484-512.

Green DW (1998) Mental control of the bilingual lexico-semantic system. Bilingualism Lang Cogn 1:67-81.

Hahne A, Friederici AD (2002) Differential task effects on semantic and syntactic processes as revealed by ERPs. Cogn Brain Res 13:339-356.

Hernandez A, Li P, MacWhinney B (2005) The emergence of competing modules in bilingualism. Trends Cogn Sci 9:222-225.

Hernandez AE, Kohnert K (1999) Aging and language switching in bilinguals. Aging Neuropsychol Cogn 6:6-83.

Hernandez AE, Martinez A, Kohnert K (2000) In search of the language switch: an fMRI study of picture naming in Spanish-English bilinguals. Brain Lang 73:421-431.

Hernandez AE, Dapretto M, Mazziotta J, Bookheimer S (2001) Language 
switching and language representation in Spanish-English bilinguals: an fMRI study. NeuroImage 14:510-520.

Humphries C, Willard K, Buchsbaum B, Hickok G (2001) Role of anterior temporal cortex in auditory sentence comprehension: an fMRI study. NeuroReport 12:1749-1752.

Jackson GM, Swainson R, Cunnington R, Jackson SR (2001) ERP correlates of executive control during repeated language switching. Bilingualism Lang Cogn 4:169-178.

Jackson GM, Swainson R, Mullin A, Cunnington R, Jackson SR (2004) The ERP correlates of a receptive language switching task. Q J Exp Psychol 57:223-240.

Kroll JF, Stewart E (1994) Category interference in translation and picture naming: evidence for asymmetric connections between bilingual memory representations. J Lang Mem 33:149-174.

Kroll JF, Bobb SC, Wodniecka Z (2006) Language selectivity is the exception, not the rule: arguments against a fixed locus of language selection in bilingual speech. Bilingualism Lang Cogn 9:119-135.

Mariën P, Abutalebi J, Engelborghs S, De Deyn PP (2005) Acquired subcortical bilingual aphasia in an early bilingual child: pathophysiology of pathological language switching and language mixing. Neurocase 11:385-398.

Meuter RF, Allport A (1999) Bilingual language switching in naming: asymmetrical costs of language selection. J Mem Lang 40:25-40.

Miller EK, Cohen J (2001) An integrative theory of prefrontal cortex function. Annu Rev Neurosci 24:167-202.

Moreno EM, Federmeirer K, Kutas M (2002) Switching languages, switching palabras (words): an electrophysiological study of code-switching. Brain Lang 80:188-207.

Oldfield RC (1971) The assessment and analysis of handedness: the Edinburgh inventory. Neuropsychologia 9:97-113.

Pallier C, Dehaene S, Poline JB, LeBihan D, Argenti AM, Dupoux E, Mehler J (2003) Brain imaging of language plasticity in adopted adults: can a second language replace the first? Cereb Cortex 13:155-161.

Paradis M (1998) Language and communication in multilinguals. In: Handbook of neurolinguistics (Stemmer B, Whitaker H, eds), pp 417430. San Diego: Academic.

Paradis M (2004) A neurolinguistic theory of bilingualism, Chap 6. Amsterdam: John Benjamins.

Paulesu E, Frith CD, Frackowiak RS (1993) The neural correlates of the verbal component of working memory. Nature 362:342-345.

Perani D, Abutalebi J (2005) Neural basis of first and second language processing. Curr Opin Neurobiol 15:202-206.

Perani D, Dehaene S, Grassi F, Cohen L, Cappa SF, Dupoux E, Fazio F, Mehler J (1996) Brain processing of native and foreign languages. NeuroReport 7:2439-2444.

Perani D, Paulesu E, Sebastian-Galles N, Dupoux E, Dehaene S, Bettinardi V,
Cappa SF, Fazio F, Mehler J (1998) The bilingual brain: proficiency and age of acquisition of the second language. Brain 121:1841-1852.

Perani D, Abutalebi J, Paulesu E, Brambati S, Scifo P, Cappa SF, Fazio F (2003) The role of age of acquisition and language usage in early, highproficient bilinguals: an fMRI study during verbal fluency. Hum Brain Mapp 19:179-182.

Price CJ, Green D, von Studnitz RA (1999) Functional imaging study of translation and language switching. Brain 122:2221-2236.

Proverbio AM, Leoni G, Zani A (2004) Language switching mechanisms in simultaneous interpreters: an ERP study. Neuropsychologia 42:1636-1656.

Rodriguez-Fornells A, Rotte M, Heinze HJ, Noesselt T, Münte TF (2002) Brain potential and functional MRI evidence for how to handle two languages with one brain. Nature 415:1026-1029.

Rodriguez-Fornells A, van der Lugt A, Rotte M, Britti B, Heinze HJ, Muente TF (2005) Second language interferes with word production in fluent bilinguals: brain potential and functional imaging evidence. J Cogn Neurosci 17:422-433.

Scott SK (2005) Auditory processing — speech, space and auditory objects. Curr Opin Neurobiol 15:197-201.

Scott SK, Blank CC, Rosen S, Wise RJ (2000) Identification of a pathway for intelligible speech in the left temporal lobe. Brain 123:2400-2406.

Segalowitz N, Hulstijn J (2005) Automaticity in bilingualism and second language learning. In: Handbook of bilingualism: psycholinguistic approaches (Kroll JF, de Groot AB, eds), pp 371-388. New York: Oxford UP.

Smith EE, Jonides J (1999) Storage and executive processes in the frontal lobes. Science 283:1657-1661.

Spitsyna G, Warren JE, Scott SK, Turkheimer FE, Wise RSJ (2006) Converging language streams in the human temporal lobe. J Neurosci 26:7328-7336.

Talairach J, Tournoux P (1988) Co-planar stereotaxic atlas of the human brain. 3-Dimensional proportional system: an approach to cerebral imaging. New York: Thieme Medical.

Thompson-Schill SL, D’Esposito M, Aguirre GK, Farah MJ (1997) Role of left inferior prefrontal cortex in retrieval of semantic knowledge: a reevaluation. Proc Natl Acad Sci USA 94:14792-14797.

Wang Y, Xue G, Chen C, Xue F, Dong Q (2007) Neural bases of asymmetric language switching in second-language learners: an ER-fMRI study. NeuroImage 35:862-870.

Wartenburger I, Heekeren HR, Abutalebi J, Cappa SF, Villringer A, Perani D (2003) Early setting of grammatical processing in the bilingual brain. Neuron 37:159-170.

Zink CF, Pagnoni G, Chappelow J, Martin-Skurski M, Berns GS (2006) Human striatal activation reflects degree of stimulus saliency. NeuroImage 29:977-983. 